\title{
Lexical Elaboration: Some Examples from the Dictionary of American Regional English*
}

\author{
FREDERIC G. CASSIDY
}

\section{$\mathrm{I}_{\mathrm{r}}$}

T IS A COMMONPLACE that a writing system simplifies the actualities of speech. It not only leaves out many prosodic features and everything allophonic, but once established as "standard orthography" it loses touch with lexical variation: the standard form is taken as the "only right" one and variants remain unobserved, unrecorded, and even disbelieved. To increase the size of the written corpus is no remedy-it merely increases the number of standard forms. Only a large corpus of spoken forms can give a true picture of the great variety that exists regionally and on different social levels. And only by noting these spoken variants can we see the extent to which variation is random or patterned and discover underlying causes.

The Dictionary of American Regional English (DARE) has compiled such a corpus of present-day spoken American English. By use of 1,002 questionnaires, each having 1,623 questions in set form, all presented orally by fieldworkers and answered orally by native informants in 50 states, a data bank of over two million responses has been compiled and sorted. The number of variants has proved unexpectedly large, but more than that, we find that some of these forms are serially elaborated, one apparently leading to another in direct or branching sequences. Not that these sequences are predictable: when numerous small changes are equally possible and speakers even in the same speech-community go in different directions, divergence is inevitable. An elaborative process is the result. Consciousness of a standard form may have some inhibiting effect, but most of the time the speaker is probably not conscious of spelling-he is just talking normally. On occasion he becomes conscious of the "right" form of a word only to play with it, making humorous alterations. An unfamiliar word or phrase, heard for the first time, is almost certain to be reproduced with some change. The conditions favoring variation and lexical elaboration include the following:

* Fran Utley was always a warm friend of $D A R E$, contributing examples of regional usage and especially helping to raise funds for the project in Ohio. This small sample of "first findings" would have interested and, I think, gratified him.-F.G.C. 
1. The form is unknown to the hearer or is indistinctly spoken: the hearer does not recognize it.

2. The hearer, in order to retain and later to reproduce this unfamiliar form, must change it to fit into his existing language system.

3. The kinds of changes in the form "as he heard it" that will bring it into his system include:

a. Substitution of phonemes more or less similar (voiced for voiceless consonants, front spirants for back, vocalization, rhotacism, assimilation, etc.).

b. Rearrangement of phonemes (metathesis, metanalysis, etc.).

c. Insertion or omission of phonemes to satisfy phonotactic, analogic, prosodic, and other requirements (epenthesis, aphaeresis, apocope, syncope, etc.).

d. Semantic reanalysis which produces an output form that "makes more sense" than the input form as he heard it (folk-etymology).

e. Metaphoric treatment (personification, etc.).

Under 3, $a, b$, and $c$ are phonetic; $d$ and e are semantic. Under the stated conditions any of these changes is possible but none is required. Lexical elaborations are most likely to occur with old-fashioned and foreign-language terms: it is a common byproduct of their adoption. The $D A R E$ corpus contains a great many series of variants, of which we present only seven examples.

Informants were asked for words and phrases they used to describe especially strong coffee (DARE Question $\mathrm{H74A})$. One series follows.

\author{
1. As strong as aqua fortis (Informant TN5) \\ 2. As strong as Aggie Fortis (TX3) \\ 3. As strong as 40 axes (TX52) \\ 4. As strong as 40 oxes (IN7)
}

No. 1 is "standard." No. 2 seems due to personification (the capital letters were not spoken, of course; they are editorially supplied). No. 2 might also be seen as a form of folk-etymology. No. 3 introduces a remarkable metathesis not of phonemes but of morpheme bases, again with folketymology. No. 4 changes one member of the simile and, by alteration of a single phoneme, totally remakes the semantic content.

It is quite unnecessary that the identity of Aggie Fortis be known: he or she may be taken for granted as obviously a very strong person-that is all the simile requires. Nor can anybody well deny the strength of $\mathbf{4 0}$ axes or oxes (a common recent plural alongside ox, oxen, oxens). The fact that these expressions are found in use over a fairly wide area (TN, IN, TX) probably implies that the expression was once widespread, since currency is essential to the proliferation of variants. But evidence on this point is inconclusive. Etymological probability is the guide here.

Another question (II26) concerned ways of denying that one knows another person: "I wouldn't know him from --.--.." Among the several hundred different responses made, the following sequence occurred: 
... from 1. Adam's off ox (63 responses from 37 states)

2. Adam's all fox (OH63, WI also heard)

3. Adam's old fox (CA53, IN22)

4. Adam's old ox (OH45)

5. Madam's off ox (MP73)

The "off" ox in an ox-team is the one farther from the driver-hence the one on the right, since he drives from the left. These phrases would seem to be jocular and perhaps emphatic extensions of "I wouldn't know him from Adam," the commonest phrase of all (556 responses).

In this sequence, no. 1 is clearly the base. No. 2, starting from /'of' $\mathrm{sks} /$, shifts the stress and juncture point to produce */' $\mathrm{o}$ 'foks/; then, evidently assuming that an $/ 1 /$ has been vocalized out, "restores" it, thus producing /'ol'foks/: all fox. Semantically there is no improvement: all fox is as obscure to the hearer as off ox must have been. Once the $/ 1 /$ is restored, however, the stage is set for folk-etymology to produce nos. 3 and 4. No. 5 requires metanalysis of "from Adam's" to "from Madam's" and may be an individualism, since the same informant also responded with "from Madam's house-cat." Folketymology may also be at work here though it does not improve familiarity of the final form.

Other things owned by Adam which the speaker says he would not know the stranger from are:

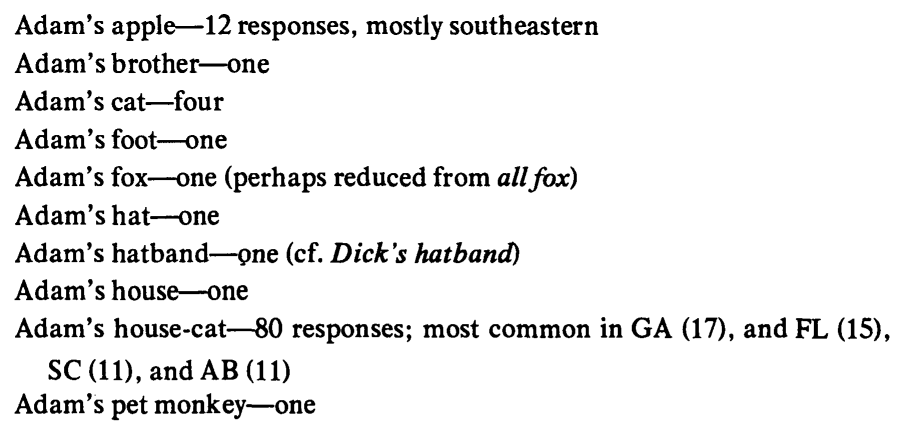

The base of this expression is, then, I wouldn't know him/her from Adam ('s + noun), and the commutable nouns are as listed. The housecat is even less recognizable than the off ox ( 80 responses vs. 63 ), but it is the unfamiliarity of the ox that produces the elaboration of variants. That the expression continues to be current despite its loss of clear meaning implies that it is old and must have been well entrenched. With the disappearance of draft oxen and the increase in urban population, everything favors survival of the house-cat, though its present currency is regional.

A well-known dance, ultimately from Warsaw, comes in for some 
interesting variations (Question FF5A):

\author{
1. varsoviana (SD) \\ 2. varsuviana (CL, NM) \\ 3. varsovienne $(\mathrm{AZ}, \mathrm{SC})$ \\ 4. vesuviano (NM) \\ 5. vizuviana $(\mathrm{PA})$ \\ 6. visacuvin (CA) \\ 7. parsuviann (SD) \\ 8. suviana (NM) \\ 9. suvian (OR)
}

This dance is favored in Mexico and the Southwest, and no. 1 is the Spanish form of its name-taken here (and in the Merriam-Webster International Dictionary, 3d edition) as the base form despite its having appeared only once in the $D A R E$ data. The /o/ most frequently closes to $/ \mathrm{u}$ ', however (all but nos. 1 and 3). No. 3 is the French form, perhaps directly introduced (into SC where French influences have been strong?) or perhaps gallicized from the Spanish form. No. 4 sounds Italian-perhaps Vesuvius, by some association of sound or metaphor, hovers in the background-but it may be simply anglicization, the initial syllable, unstressed, losing its $/ r /$, and the /o/ representing "Spanish" for the Anglo.

Anglicization, in a word of this stress pattern, clearly involves reduction of stress on the initial syllable. The effects are evident in nos. $4,5,6,8$, and 9. In nos. 5 and $6, i$ represents /a/; in no. 5 intervocalic $/ \mathrm{s} /$, unstressed, is voiced to $/ \mathrm{z} /$. In nos. 8 and 9 the entire first syllable goes, and 9 at least achieves complete anglicization with first-syllable stress and loss of final - $a$. In no. 7 the substitution of $/ \mathrm{p} /$ for $/ \mathrm{v} /$ is somewhat unexpected, but both are labial. The final syllable hints at possible personification.

The name of an herb commonly used to make a medicinal tea, pennyroyal, shows a short but interesting elaboration (BB50A). Pennyroyal is already the result of an old folk-etymology, having come from Latin pulegium + regalis through Anglo-French puliol real to Middle English pulyole ryale. But it continues to change:

\footnotetext{
1. pennyroyal, often pronounced /'peni'rai(ə)1/

2. penner oil (IL)

3. pender oil (WV)
}

In nos. 2 and 3 the juncture point and stress are shifted to follow the /r/; reanalysis, with folk-etymology, is the result. In this case the semantic alteration is certainly toward the more familiar oil, with its importance in folk remedies. The excrescent / $\mathrm{d} /$ of pender is due to asynchrony: the velum is raised before release of the alveolar closure. As elaborations go, 
this is simple: the output form is clearly "more meaningful" than the input form. The impulse to change is proportional to the unfamiliarity, and once this is reduced the impulse may be satisfied. But since penner and pender make no obvious sense, further change may occur later.

"To make a short visit or call" (DARE II14) might be described almost anywhere in the English-speaking world with the verb phrase to pop in. Elaborations from this base have developed as follows:

1. pop call—adj. + noun (18 responses, especially from GA, also FL, KY, LA,

NC, PA, SC, TN)

2. pop-in call—adj. (from an infinitive) + noun (TX)

3. popcorn call-attrib. + noun (GA, TN)

4. pop-call-verb (four responses: FL, GA, NC, SC)

5. popcorn-call-verb (one response: TN)

Pop call is clearly regional and well established in the Southeastern states. No. 4, its verb, is from the same area. Pop call was used by both blacks and whites in normal proportions. Fieldworkers unfortunately gave no explanation of popcorn call: it would be interesting to know whether callers expect to be treated to a feast of popcorn, whether the call takes no longer than the time to pop corn (and eat it?), or what other way it is thought of.

But lexical elaboration can go much further, as in the $D A R E$ question (W1) which asks for other names for an umbrella (A), for a parasol (B), and humorous terms for an umbrella or parasol (C). The umbrella is evidently considered a proper object of humor. Elaborations seen so far are mainly unconscious; here there is also a conscious element. Umbrella and parasol undergo the usual phonetic alterations, but much ingenuity also goes into jocular distortions involving sound-play and sense-play. The resultant forms sort themselves out as follows:

1. umbrella-most common; standard.

2. umberella-121 responses. The epenthetic $/ /$ perhaps aids pronunciation.

3. umberell-five responses; simplification of no. 2 .

4. umberelly-one response; old fashioned variant of 2.

5. bumberella-one response; initial $/ \mathrm{b} /$ added by anticipation of internal $/ \mathrm{b} /$.

6. unclebella-humorous distortion.

7. numberbelly-humorous distortion.

8. underbrella

9. headbrella

10. sunbrella

one response each; blends substituting more meaningful words for um-

11. sunberella

12. rainberella 
Alongside this elaborated series there is another based on parasol:

1. parasol-most common; standard

2. parasole )

3. parashol $\}$ one response each; substitution of phonemes.

4. parasoil

5. parachute or -shoot-56 responses; for both parasol and umbrella.

6. paraboo-one response; obscure association.

Noteworthy here is the large number of examples of no. 5. Shoot probably comes closer than chute to the way the word is understood: I take it to be folk-etymology referring to how an umbrella opens-one shoots it open, or it shoots up when opened. In any case, shoot becomes the basis for an entire new elaboration, a parallel series using -sol, and both having umber- as the first element:

$\begin{array}{ll}\text { umbershoot-15 resp. } & \text { umbersol-four resp. } \\ \text { bumbershoot-eight resp. } & \text { bumbersol-four resp. } \\ \text { bumpershoot-45 resp. } & \text { bumpersol-one resp. }\end{array}$

Finally, from bumbershoot follow half a dozen variants:



Nos. 1 and 2 have $/ 1 /$ substitution for $/ \mathrm{r} /$. In no. 4 the first $/ \mathrm{r} /$ is due to anticipation of the second $/ \mathrm{r} /$. Nos. $1,3,5,6$, and bumpershoot share a semantic element suggesting clumsiness. Do people carrying umbrellas blunder, bumble, and bump into each other? Or are the explosive consonants merely phonosymbolic? And in no. 2 is there a reference to walking with an umbrella? Many factors are active or possibly active. The extent of this particular series shows how far elaboration can go.

Singly, any one of these variations seems trivial enough; it is only when a large corpus of examples from all over the country is brought together that the range and sequence of changes is seen to form patterns. With a full body of data the etymologist has fewer gaps to jump and need not so often resort to that familiar but uncomfortable label "Etym. uncert." 